Graciele de Souza Colling- FURB ${ }^{1}$

Rita Buzzi Rausch - FURB ${ }^{2}$

\title{
INTRODUÇÃO
}

A busca por uma formação docente comprometida com a educação, voltada para a especificidade da Educação Infantil, visa uma reflexão acerca do faz-de-conta e das culturas infantis. Ao longo dos séculos, o cuidado e a educação das crianças que hoje são consideradas integrantes da Educação Infantil foram atribuídos unicamente à família. Para Sarmento e Pinto (1997), é neste contexto que se fala do adultocentrismo, como o acúmulo de obstáculos ao conhecimento da realidade de ser criança. Apontado também o adultrocentrismo, como problema das pesquisas sobre as crianças, pelo fato das pesquisas serem realizadas com pessoas que respondiam por elas, sejam pais, sejam professores. Posteriormente, foram surgindo pesquisas a fim de estudar o faz-de-conta e as culturas infantis e dar vozes às crianças.

A compreensão das brincadeiras de faz-de-conta e das culturas infantis podem contribuir com a reflexão das professoras sobre a relevância dessa dinâmica na construção do conhecimento das crianças e sobre o espaço disponibilizado às brincadeiras de faz-de-conta no cotidiano da instituição. Para Redin (2009), o tempo da infância é curto, a criança é projetada para o futuro, porém a criança precisa ser vista como ser do presente. Esta pesquisa relacionada ao tema da Infância visa contribuir com os estudos que consideram a criança como ser social do presente. No cotidiano da Educação Infantil cada vez mais a criança é privada de brincar e a escolarização ou "dever de aluno" direciona a criança a uma rigorosa rotina institucional. Partindo destes pressupostos, seguidos da pergunta de partida a qual pretendemos elencar aos objetivos da pesquisa, nos propomos a investigar qual a compreensão das professoras que atuam com crianças de três a quatro anos no Município de

\footnotetext{
${ }^{1}$ Mestre em Educação. Professora de Educação Infantil da Rede Municipal de Gaspar: E-mail: grazicolling@hotmail.com.

${ }^{2}$ Doutora em Educação pela UNICAMP. Docente-pesquisadora na Universidade Regional de Blumenau FURB. E-mail: rausch@,furb.br
} 


\section{COMPREENSÃO DE PROFESSORAS ACERCA DAS BRINCADEIRAS \\ DE FAZ-DE-CONTA E DAS CULTURAS INFANTIS}

Gaspar, acerca das brincadeiras de faz-de-conta e das culturas infantis no cotidiano da instituição de Educação Infantil?

Para a concretização da pesquisa elaboramos diante dos objetivos, entrevistas estruturadas com onze professoras. As perguntas da entrevista foram voltadas ao tema da pesquisa que, por sua vez traz relação com os estudos de Willian Corsaro (2002), sendo a perspectiva de investigação desse autor os aspectos das culturas infantis no faz-de-conta das crianças e de como acontece a reprodução interpretativa entre pares. Trazemos, também, os estudos de Manoel Jacinto Sarmento (2004) sobre alguns paradoxos da infância e a consideração da criança como ator social. O autor Maurice Tardif (2002), Selma Garrido Pimenta (2000) e Silvia Vieira Cruz (2010) nos auxiliaram nas discussões da formação profissional e dos saberes docentes.

\section{A REPRODUÇÃO INTERPRETATIVA NA INTERAÇÃO ENTRE PARES E O FAZ-DE- CONTA}

Para desenvolver essa pesquisa partimos de dois pressupostos básicos. O primeiro pressuposto é de que a infância é uma construção social. O segundo de que a criança é um ator social, por isso produtora/ reprodutora de cultura. Para Cohn (2005, p. 27-28), "a criança atuante é aquela que tem um papel ativo na constituição das relações sociais em que se engaja, não sendo, portanto passiva na incorporação de papéis e comportamentos sociais". Concordamos com a autora que a criança atuante não é passiva na apropriação de papéis, mas compreendida como um ser de capacidades e especificidades cognitivas próprias que realiza descobertas por meio de suas experiências, devendo ser respeitada pelos adultos como seres de direito.

Estudar as culturas e interpretá-las pode ser algo bastante complexo, por ater-se a dados coletados de maneira densa e dedicada os quais propiciaram a aproximação autêntica da realidade estudada. Propor-se ao estudo acerca do tema das culturas infantis e do faz-de-conta não é diferente nem menos complexo. A Sociologia da Infância é uma recente disciplina instituída a partir dos anos 80 que surge para tratar das questões da infância, também chamada de "novos estudos sociais da infância".

A cultura de pares é determinada por Corsaro (2009, p. 32) como: “defino cultura de pares como um conjunto estável de atividades ou rotinas, artefatos, valores e interesses que as 


\section{COMPREENSÃO DE PROFESSORAS ACERCA DAS BRINCADEIRAS \\ DE FAZ-DE-CONTA E DAS CULTURAS INFANTIS}

crianças produzem e compartilham na interação com seus pares". As crianças observam os adultos e interpretam suas ações de acordo com seu interesse. Conforme as crianças vão se apropriando de situações do universo dos adultos, elas também apresentam condições e capacidade de produzir/reproduzir a cultura de pares. Os estudos de Corsaro (2002) referemse às culturas infantis enfatizando a maneira das crianças constituírem grupos para desempenhar atividades de faz-de-conta relacionadas às experiências de vida reais e cotidianas. O autor define as culturas infantis como um conjunto de atividades, valores, preocupações que as crianças produzem e compartilham entre si na interação de pares.

Para Vygotsky (1989), num sentido mais abrangente, tudo aquilo que é cultural é social, pois o social é um elemento mais antigo que a cultura, sendo uma das características de certas formas de vida, o que os permite relacionar a uma sociabilidade natural. Anterior à cultura, o social dentro dela adquire formas humanas de existência. O social é considerado como forma de condição e resultado do aparecimento da cultura, isso porque as formas de sociabilidade são produções humanas e, portanto culturais. A cultura é entendida por esse autor como prática social resultante da dinâmica das relações sociais que caracterizam uma determinada sociedade.

Nesse aspecto, Sarmento (2004, p. 22) destaca que "as culturas da infância exprimem a cultura societal em que se inserem, mas fazem-no de modo distinto das culturas adultas, ao mesmo tempo em que veiculam formas especificamente infantis de inteligibilidade, representação e simbolização do mundo". As culturas infantis não se reduzem, nem se limitam à produção adulta, mas apresentam traços distintivos que são reconhecidos e distintos nas culturas da infância. $\mathrm{O}$ fato é que as culturas infantis explanam aspectos sociais em que as crianças estão inseridas de maneira a interpretar, reinventar, conhecer e modificar o mundo que as cercam.

Conforme Sarmento (2004, p. 24), “a convivência com seus pares, através de rotinas e da realização de atividades, permite-lhes exorcizar medos, representar fantasias e cenas do cotidiano, que assim funcionam como terapias para lidar com experiências negativas". As crianças podem superar seus problemas por meio de suas atividades e experiências cotidianas. Valendo-se de sua imaginação e por meio do faz-de-conta representam cenas nas quais não conseguem compreender/ superar na vida real, ou seja, as crianças obtêm por meio da fantasia e das interações entre si, a possibilidade de compartilhar ações, situações e emoções imprescindíveis ao entendimento do mundo ao que pertencem. 


\section{COMPREENSÃO DE PROFESSORAS ACERCA DAS BRINCADEIRAS DE FAZ-DE-CONTA E DAS CULTURAS INFANTIS}

Os direitos fundamentais das crianças legitimados no Brasil pelo Estatuto da Criança e do Adolescente - ECA, em 1990, traz especificada nos direitos fundamentais da criança em três eixos: proteção, provisão e participação. No entanto, é importante que todos os estudos realizados até a atualidade sobre a infância permitem compreendermos a importância da brincadeira como um elo com cada um desses três eixos, razão pela qual todo educador poderá refletir maneiras de disponibilizar os momentos de brincadeiras de faz-de-conta para as crianças como ferramenta essencial no seu desenvolvimento. Incluir em seu planejamento as brincadeiras de faz-de-conta das crianças como item essencial às suas observações e registros. A brincadeira é uma maneira da criança se expressar, uma forma de atividade social infantil, cuja característica imaginativa é uma ocasião de aprendizado para a criança, pois é na e através das brincadeiras que a criança traz do universo dos adultos elementos reais para representar (nas brincadeiras) construindo conhecimentos e produzindo/ reproduzindo culturas.

Podemos considerar o brincar de faz-de-conta como um propulsor da reprodução interpretativa da cultura de pares. Uma importante contribuição para podermos compreender como as crianças vão construindo seus conhecimentos de forma processual tomando informações dos adultos e refinando para a cultura de pares ao brincar de faz-de-conta. Existem mecanismos utilizados pelas crianças para participar do mundo dos adultos, o qual traz informações para a brincadeira na tentativa de compreender questões que na realidade não conseguem. As crianças transformam as informações em conhecimentos necessários para poderem participar do meio adulto. As crianças não somente internalizam essas informações, mas utilizam como mecanismos de compreensão do mundo adulto que lhe é externo, e por meio da reprodução interpretativa na brincadeira de faz-de-conta demonstram concomitantemente a produção criativa na cultura de pares. Ao observar as crianças e suas manifestações culturais percebemos como ela vai atribuindo significados às coisas, dando sentido aos objetos e elementos, trazendo para o faz-de-conta "falas" interessantes que vão evidenciando essa cultura produzida na infância tão importante para o seu desenvolvimento e apropriação de conceitos pelas crianças.

Concordamos com Sarmento (2004), quando explica que o brincar é a condição da aprendizagem das crianças e consequentemente da aprendizagem da sociabilidade. Por isso a brincadeira está presente nas relações das crianças entre si e nas fases da construção das suas relações com o outro. Por meio da brincadeira de faz-de-conta as crianças se apropriam de 


\section{COMPREENSÃO DE PROFESSORAS ACERCA DAS BRINCADEIRAS \\ DE FAZ-DE-CONTA E DAS CULTURAS INFANTIS}

conceitos e aprendem a estabelecer relações sociais entre si. O brincar torna-se fator essencial a sua aprendizagem, pois a brincadeira é algo sério para as crianças, ela vivencia a situações imaginárias com muita autenticidade. Quando cria, constrói e reconstrói situações imaginárias baseadas na sua realidade o brincar de faz-de-conta permite às crianças legitimar suas ações, torna-se a elas personagens situações reais. É como se as crianças se encontrassem em outro lugar, outro ambiente, outra pessoa e/ou personagem, pois utilizam a imaginação de forma fidedigna.

A brincadeira é representada como uma atividade social e através dela a criança desenvolve de maneira ampla as suas habilidades físicas e cognitivas. Durante as brincadeiras de faz-de-conta as crianças experimentam, investigam, inventam, constroem regras, organizam seus pensamentos, estabelecem relações em diversas situações. As brincadeiras de faz-de-conta e as manifestações culturais são paralelas, pois à medida que as crianças vão organizando suas brincadeiras de faz-de-conta trazem do universo dos adultos aspectos culturais. Para compreender essa importância é necessário analisar os aspectos que desencadeiam essa proposta e como acontece essa relação, o ambiente, os momentos destinados às brincadeiras de faz-de-conta e as pessoas nelas envolvidas. Por isso se o professor tiver clareza do significado do faz-de-conta para as crianças e proporcionar maiores momentos de interação entre as mesmas, permite que as crianças façam suas próprias escolhas com mais autonomia.

Partimos do ponto de vista de que tudo o que as crianças presenciam no cotidiano influencia nas suas brincadeiras de faz-de-conta, as crianças reproduzem aquilo que observam. A brincadeira de faz-de-conta também transcende a realidade imediata, ou seja, há outras realidades sociais que influenciam e fazem intercâmbio com a realidade das crianças na interação com outras dimensões e/ou outras crianças com realidades diferentes da sua. No entanto, não há como mencionar o brincar de faz-de-conta sem mencionar crianças e não há como deslocar o assunto sobre as crianças dos adultos, dessa maneira ao mencionar estes três elementos estamos falando também das culturas.

A organização social típica das sociedades industriais, e a ampliação do universo cultural com o qual a criança passa a interagir, rompem com os padrões instituídos de uma educação infantil que se dá, sobretudo, no interior da família e sob uma orientação particular própria, baseada em valores específicos dos grupos sociais familiares. Estas transformações nos impõem uma reflexão acerca da responsabilidade social sobre a criança. Dessa forma, a 


\section{COMPREENSÃO DE PROFESSORAS ACERCA DAS BRINCADEIRAS \\ DE FAZ-DE-CONTA E DAS CULTURAS INFANTIS}

educação infantil precisa ser vista como uma tarefa pública socialmente compartilhada, que se reflete em políticas públicas que respeitam os direitos da criança e associam-se, freqüentemente, às políticas sociais voltadas para a família, com o intuito de viabilizar uma educação que contemple as múltiplas dimensões humanas. Outro aspecto importante merece destaque na construção de uma Pedagogia da Educação Infantil está relacionada à concepção de infância, isto por tradicionalmente utilizar-se a concepção de criança homogênea, onde a delimitação tem sido feita pela imaturidade da criança e pela falta em relação ao adulto. Mas, como afirma Cerisara (2002), a infância se apresenta como tema multidisciplinar, objeto de diferentes campos disciplinares tais como a Sociologia, a Antropologia, História, Psicologia, em que a infância tem que ser vista não apenas na sua dimensão biológica, mas como fato social e que por refletir as variações da cultura humana é "heterogênea".

Partindo de pressupostos de Rocha (1999), a Pedagogia da Infância trabalha com a concepção de criança para além do aluno, cuja perspectiva se torna o centro da construção de práticas pedagógicas menos centradas nos pontos de vista dos adultos, uma vez que esta Pedagogia considera legítima a voz das crianças, além de considerá-las construtoras em conjunto dessas práticas. Entretanto, torna-se necessário estabelecer as diferenças entre a instituição de Educação Infantil e a de Ensino Fundamental, para se definir os objetivos centrais da Pedagogia da Infância, no sentido de compreender que cada uma possui intencionalidade educativa diferentes. Podemos dizer que na sociedade brasileira atual, tais instituições em termos de organização do sistema educacional e da legislação apresentam contornos bem definidos. Enquanto a escola se coloca como o espaço privilegiado para o domínio dos conhecimentos básicos, as instituições de educação infantil se põem, sobretudo, com fins de complementaridade à educação da família. Enquanto, a escola tem como sujeito o aluno, e como objeto fundamental o ensino nas diferentes áreas, através da aula, a creche e a pré-escola têm como objeto as relações educativas travadas num espaço de convívio coletivo e têm como sujeito a criança de 0 a 6 anos de idade (ou até o momento em que entra na escola).

Para compreender as crianças e como elas produzem/ reproduzem culturas é necessário compreendê-las como ativas do ambiente que as cercam. Para Delgado e Muller (2005), as socializações das crianças nos permitem compreendê-las como atores sociais com habilidades para transformar a sua cultura, mesmo inserida no mundo dos adultos, as crianças ao interagir no universo dos adultos compartilham e produzem suas culturas atribuindo 


\section{COMPREENSÃO DE PROFESSORAS ACERCA DAS BRINCADEIRAS \\ DE FAZ-DE-CONTA E DAS CULTURAS INFANTIS}

significados ao seu universo infantil, capazes de fazer modificações e interpretar aquilo que vivencia da cultura adulta.

Nas brincadeiras as crianças têm a oportunidade não apenas de vivenciar as regras impostas, mas de transformá-las e recriá-las de acordo com as necessidades em entendê-las. É por meio das brincadeiras de faz-de-conta que as crianças agem como se fossem outra figura. Mesmo sem a intenção de aprender, elas constroem conhecimentos. O faz-de-conta para as crianças consiste em liberdade de criação em que podem expressar sensações, emoções e ideias sobre o mundo promovendo a interação com o outro, representa o mundo da fantasia, da imaginação fundamental para o seu desenvolvimento. Para o adulto torna-se mais difícil a tarefa de interpretar as vozes das crianças, por meio de observações, estudos etnográficos e métodos investigativos, pois o olhar do adulto passa despercebido vários fatores presentes nas relações entre as crianças, é necessário um olhar bem atento às manifestações culturais e suas possíveis fontes. As origens das organizações das brincadeiras das crianças nos remetem a reflexão com intuito de compreender os motivos pelos quais as crianças se relacionam desta ou daquela maneira. A brincadeira pode ser vista como um processo de relações construídas pelas crianças seja com o ambiente, entre as crianças e entre criança e adulto. É de extrema relevância para o desenvolvimento infantil, pois permite à criança refletir, desorganizar e reconstruir o mundo a sua maneira, incluindo fatores intelectuais, históricos, culturais e sociais. Os estudos culturais envolvem também possibilidades estimulantes de maneiras inovadoras de estudar a educação infantil e de como a criança se vincula à cultura infantil. Estudos culturais infantis são necessários à consideração das crianças como atores sociais conforme Sarmento e Pinto (1997) consistem em reconhecer a criança como seres capazes de representações consideradas pelos estudos científicos representações em sistemas simbólicos, de culturas produzidas pelas crianças, ou seja, "culturas infantis".

\section{METODOLOGIA}

A presente pesquisa abordou como tema as culturas infantis e as brincadeiras de faz-deconta das crianças numa perspectiva docente. Esta pesquisa foi de caráter qualitativo. $\mathrm{Na}$ abordagem qualitativa, o pesquisador dá mais ênfase ao processo da pesquisa do que dados numéricos, ou seja, a preocupação está mais voltada ao contato do pesquisador com as situações, os estudos, as experiências, traçando o fato de como se dá sentido as coisas por meio das pessoas investigadas, o que caracteriza relevância fundamental do significado na 


\section{COMPREENSÃO DE PROFESSORAS ACERCA DAS BRINCADEIRAS \\ DE FAZ-DE-CONTA E DAS CULTURAS INFANTIS}

abordagem qualitativa (BIKLEN e BODGAN, 1994). Buscou analisar as compreensões de um grupo de professoras em relação às culturas infantis e ao brincar de faz-de-conta das crianças no contexto de Educação Infantil. Para entender melhor este conceito, realizamos estudos teóricos de alguns autores no campo da Sociologia da Infância. Posteriormente, realizamos a coleta de dados que foi realizada entre os meses de abril a junho de 2010, entrevistas estruturadas, gravadas e transcritas com onze professoras de crianças de três a quatro anos de idade dos Centros de Desenvolvimento Infantil do Município de Gaspar.

A transcrição e organização dos dados se deram conforme as entrevistas iam sendo realizadas. De acordo com Quivy e Campenhoudt (1993), a entrevista é uma técnica especialmente adequada para a investigação social que objetiva a análise do sentido que os atores dão às suas práticas e para a compreensão dos sistemas de valores e referências normativas, tendo como vantagem o grau de profundidade dos elementos de análise recolhidos, respeitando os quadros de referência, a linguagem e as categorias mentais dos agentes investigadores.

Após a leitura minuciosa das entrevistas transcritas, organizamos a análise desta pesquisa em quatro eixos de significação. O primeiro eixo de significação está voltado ao à compreensão do significado do brincar de faz-de-conta para as professoras; o segundo eixo refere-se aos aspectos das culturas infantis trazidos pelas crianças para as brincadeiras de fazde-conta na compreensão das professoras. Segundo Bardin (1977), a objetividade e a fidelidade precisam ser tomadas como princípios essenciais à análise do material que não terá interpretações equivocadas.

As pesquisas relacionadas às crianças e a sua educação exigem estudos em diferentes áreas. Consideramos que, na Educação Infantil, existem aspectos em relação à criança que merecem o olhar dos pesquisadores tais como: aspectos sociais, culturais, afetivos e familiares dentro de um contexto em que a criança está inserida. As oportunidades proporcionadas à criança dependem das diversas relações estabelecidas por ela, bem como as diferentes formas da criança viver a infância e suas experiências, que poderão ser marcantes e definitivas para o seu desenvolvimento integral. É o momento caracterizado por pesquisas que tendem a enfatizar as crianças vistas como sujeitos da sua ação, na relação pedagógica, entendendo-as como seres ativos na dimensão das determinações culturais em âmbito do espaço social na instituição da Educação Infantil. 


\section{O FAZ-DE-CONTA E AS CULTURAS INFANTIS NA COMPREENSÃO DAS} PROFESSORAS

As professoras que atuam com crianças de três a quatro anos da Educação Infantil da Rede Municipal de Gaspar destacaram em suas respostas o significado do brincar. Percebemos algumas semelhanças em determinadas respostas, embora o brincar das crianças seja algo subjetivo. Destacamos os conceitos das professoras por algumas características. Para três professoras entrevistadas, o brincar tem a ver com criatividade, emoção e a imaginação das crianças. Ao brincar as crianças criam e utilizam-se da imaginação trazendo suas referências para a brincadeira. Para duas professoras a brincadeira é a principal atividade das crianças no CDI, consideram a brincadeira como essencial dentro do contexto da Educação Infantil pelo fato das crianças passarem maior tempo do dia na instituição. Para cinco professoras, a brincadeira é uma forma da criança se expressar. Por meio do brincar as crianças se soltam, liberam as emoções e as suas vontades, consideram o brincar como forma de valorizar e organizar as coisas. A criança tem a capacidade de questionar aquilo que não está de acordo, o brincar como indispensável às crianças. Conceituam o brincar como forma da criança aprender. As professoras também relacionam o brincar com a aprendizagem. Segundo estas professoras, a brincadeira possui um significado para a criança. Entretanto, duas professoras responderam de maneira a projetar a criança para o futuro, preocupadas com as crianças no período em que ingressarão na escola. Para uma professora é através do brincar que a criança representa o papel de algum personagem, seja da própria professora, seja de outras pessoas.

Ao considerar o brincar das crianças como algo amplo, percebemos ainda na fala das professoras entrevistadas um conceito geral do brincar, porém quando mencionam que as crianças ao brincarem criam e imaginam, remete-nos aos aspectos da imaginação das crianças como algo que se concretiza quando a criança sente a necessidade de se relacionar com o outro e com o objeto e reinterpretar a sua realidade. A professora tem papel ativo na mediação da criança com o brincar. É neste aspecto que Colling e Iten (2008, p. 21) destacam, “o educador exerce na Educação Infantil um papel fundamental para tornar a brincadeira do fazde-conta algo significativo para as crianças". É por meio das brincadeiras de faz-de-conta que 


\section{COMPREENSÃO DE PROFESSORAS ACERCA DAS BRINCADEIRAS \\ DE FAZ-DE-CONTA E DAS CULTURAS INFANTIS}

as crianças agem como se fossem outro personagem. $\mathrm{O}$ faz-de-conta das crianças possibilita que elas criem, organizem seus pensamentos, podem expressar sentimentos, emoções e ideias sobre o mundo. Promover às crianças a interação com o outro e deixá-las utilizar a fantasia e a imaginação é fundamental para o seu desenvolvimento. Ao criar situações imaginárias a criança considera esse momento como algo sério, por isso aquilo que é brincadeira para o adulto é sério para a criança, no entanto, ela realmente internaliza a situação como se fosse a sua realidade.

Para a professora Regina conceituou o brincar como: "O brincar das crianças pra mim é a principal atividade deles no CDI. Eles estão aqui o dia inteiro. Eles passam aqui de dez a doze horas. Se eles não brincarem aqui, onde que eles vão brincar. Às vezes chegam em casa, vão para televisão ou eles vão dormir, tomar banho e dormir. Então aqui eles têm que brincar, eles têm que vivenciar diversas maneiras de brincadeiras, seja através de jogo, de atividade escrita que também pra eles passa a ser uma brincadeira, de cantar no microfone, brincar com máscara, de infinitas ideias que a gente tem pra proporcionar pra eles. Isso é muito significativo. Isso vai influenciar muito na fase adulta, na vida deles, essas vivências deles na infância aqui no CDI”. (Regina, 20/05/2010).

A consideração do brincar geralmente está focada na atividade. Mesmo que a professora considere o brincar como a principal atividade das crianças, acabam por citar a atividade escrita, o cantar no microfone, os jogos, como atividades relacionadas à brincadeira. Porém, o faz-de-conta não tem estas características. Os jogos nesta faixa etária são realizados com a presença do adulto pelo fato das crianças ainda não compreenderem algumas regras. Então, se a principal atividade é o brincar, poderia também ser algo em que as crianças escolhem os momentos que por si só desejam organizar uma brincadeira. O brincar das crianças devem acontecer também de forma espontânea, a professora neste papel organiza o espaço (físico) e as crianças brincam de faz-de-conta com diversificados elementos que instigam a imaginação. Neste aspecto, Sarmento (2004) destaca a maneira pela qual as crianças se relacionam com a família, a comunidade e com outras crianças em diversas atividades de interação. As crianças e suas relações sociais nos mais diversos espaços dentro e fora da instituição desenvolvem e constroem conhecimentos, construindo de forma paralela a sua identidade pessoal e social. 


\section{COMPREENSÃO DE PROFESSORAS ACERCA DAS BRINCADEIRAS \\ DE FAZ-DE-CONTA E DAS CULTURAS INFANTIS}

A Educação Infantil que a literatura recomenda é justamente a que privilegia a criança naquilo que lhe é próprio e específico, “o brincar”. Os estudos de Corsaro (2002, p.32), apontam que "devemos também considerar como é que diferentes características estruturais e institucionais constrangem e capacitam os processos coletivos de interesses". As crianças podem estar imersas a uma organização institucional que determinam o tempo delas em atividades sequenciais diárias que impedem que elas brinquem livremente no espaço da Educação Infantil.

Concordamos com Corsaro (2002), quando explica que para as experiências terem sentido no universo das crianças, essas experiências fazem parte de sua realidade: "refiro-me ao brincar no qual as crianças produzem colaborativamente actividades de "faz-de-conta" que são relacionadas com experiências das suas vidas reais, por exemplo, rotinas familiares e ocupacionais". (p. 115). Destaca ainda que o faz-de-conta das crianças contribui desta forma com aquisições de competências comunicacionais e conhecimento social. "brincar para a criança é um meio de expressão que simboliza suas experiências, o conhecimento de seu mundo, seus desejos, suas frustrações, seus sonhos e fantasias". (GASPAR, p.21).

Para tornar o faz-de-conta relevante na prática educativa das professoras, a dinâmica do brincar estará em destaque no planejamento docente. Podemos considerar o planejamento como um processo contínuo que compreende o que o professor quer (deseja) e o que faz (realiza). Planejar exige decisões relevantes acerca das ações a serem efetuadas, por isso necessitam de contínuas reflexões com eficácia, dedicação e um olhar atento daquilo que se quer alcançar. Concordamos com Gandin (2000), quando menciona como o planejamento pode contribuir com a realização daquilo que foi antevisto pelas profissionais para a prática, "o planejamento e um plano ajudam a alcançar com eficiência, isto é, elaboram-se planos, implanta-se um processo de planejamento a fim de que seja bem-feito aquilo que se faz dentro dos limites previstos para aquela execução". (p. 17).

Aquilo que foi mencionado pelas professoras acerca do faz-de-conta e das culturas infantis juntamente com os autores que alicerçam este trabalho, nos levaram a compreender a relevância do planejamento e da ação docente voltado à dinâmica das brincadeiras de faz-deconta no cotidiano institucional, pois somente o vínculo entre teoria e prática provocará os resultados que almejamos na Educação Infantil. Os aspectos culturais das crianças evidenciados nas brincadeiras de faz-de-conta refletem situações reais que vivenciam em seu 


\section{COMPREENSÃO DE PROFESSORAS ACERCA DAS BRINCADEIRAS \\ DE FAZ-DE-CONTA E DAS CULTURAS INFANTIS}

cotidiano. O significado dado às coisas são conceitos que as crianças constroem nesta relação entre si e as ações presentes nas brincadeiras de faz-de-conta.

A fala da professora Geice direciona ao fato da criança imitar os adultos, porém a dinâmica do brincar conforme destaca Corsaro (2002) não se restringe a imitação, mas sim como representação interpretativa entre os pares. "Bastante do que acontece em casa, principalmente quando eles brincam de mamãe e papai, o que acontece em casa eles acabam trazendo pra sala. De fazer comida na casinha é mais forte, a mamãe vai trabalhar, essas coisas. Na área da fantasia, por exemplo, a criança colocou a bolsa, colocou a roupa, o sapato e disse que ia trabalhar, é uma coisa que a mãe faz. E era um menino representando a mãe. E "outra criança que é "especial" colocou a roupa e a bolsa e disse que ia para a missa, então trouxe a realidade dele para o CDI”. (Geice, 01/06/2010).

A fantasia se reporta às situações da realidade e são estabelecidas com novos significados no faz-de-conta, trazidas de um universo de referência que é o universo dos adultos. O aprendizado das crianças nas brincadeiras de faz-de-conta manifestam aspectos do interesse da criança que utiliza sua imaginação para transformar aquele objeto ou brinquedo em algo que tenha observado e que possa ter chamado sua atenção. As crianças quando brincam de faz-de-conta aprendem além de conceitos a se relacionar com o meio social. Os conceitos que elaboram são significativos à medida que constroem entre pares interpretações pertinentes ao seu aprendizado. A abordagem interpretativa, segundo Corsaro (2002), considera a socialização como um processo produtivo-reprodutivo e crescente na reorganização do conhecimento das crianças e com as mudanças nos seus mundos sociais.

Desta maneira refletimos sobre as metodologias que direcionam o olhar das professoras para as crianças, suas vivências, pontos de vista e saberes. São desafios no campo da Sociologia da Infância que estão sendo concretizados com algumas pesquisas empíricas. Pesquisas essas que podem obter estudos das culturas e envolver muitas possibilidades que estimulam novas ideias, novas maneiras de dar atenção aos estudos da dinâmica discursiva do campo das culturas infantis abrangendo a Educação Infantil. Os estudos das culturas infantis devem estar conectados com uma pedagogia para e com as crianças, que possam envolver investigações de como a criança constrói suas relações entre si no cotidiano e no espaço da instituição da Educação Infantil, bem como, a maneira que os professores articulam as manifestações das culturas infantis. 


\section{COMPREENSÃO DE PROFESSORAS ACERCA DAS BRINCADEIRAS \\ DE FAZ-DE-CONTA E DAS CULTURAS INFANTIS}

Para Redin (2009), “conhecer as crianças enquanto grupo que se relaciona e cria sentidos e significados para o mundo requer tempo, sensibilidade e, principalmente, desprendimento de um olhar adultrocêntrico viciado". (p. 118).

Uma pergunta feita na entrevista referia-se aos aspectos culturais trazidos pelas crianças para as brincadeiras de faz-de-conta. A professora Greice nos relatou: "Isso aparece muito forte, os pontos positivos e os pontos negativos eles trazem nitidamente. Têm crianças que trazem as brigas, eles trazem principalmente as falas das mães”. (Greice, 11/05/2010).

Os estudos de Muller (2009) explicam as escolhas das crianças e os aspectos culturais vivenciados em outros ambientes de interação não institucional, mas que as crianças trazem para dentro da brincadeira de faz-de-conta. De acordo com essa autora a criança ao reproduzir no faz-de-conta os papéis de gênero apropria-se também de aspectos sociais de gênero que perpetuam seu grupo e definições sociais que contribuem para a construção de sua identidade. “Ao reproduzir elementos da cultura, a criança de certa forma os aprende e os legitima. A criança leva para a situação de brincadeira os modelos de comportamento e significados construídos em outros espaços interacionais”. (MÜLLER, 2009, p. 53).

Ao trazerem para a brincadeira de faz-de-conta as ações da mãe como destacou a professora Greice, podemos considerar a representação de gênero em que as crianças se apropriam de situações que acontecem em seu grupo social, interações, espaços e relações com o outro. Para Corsaro (2009), quando a criança reproduz os elementos da cultura dela, no entanto, os aprende e os torna legítimos, levando para a brincadeira comportamentos apropriados de outros diversos espaços de interação.

Partindo dessas reflexões e conceitos atribuídos por Corsaro (2009) em relação à cultura de pares, é possível refletirmos sobre os significados que nós adultos atribuímos às crianças e às suas culturas para educação mais especificamente para as teorias Pedagógicas. Refletimos sobre como essas questões incidem em tais teorias e por consequência na prática das professoras de Educação Infantil. Os aspectos culturais das crianças evidenciados nas brincadeiras de faz-de-conta refletem as situações reais que vivenciam. O significado dado às coisas são conceitos que as crianças constroem nesta relação entre elas e a ações presentes na brincadeira de faz-de-conta.

A resposta da professora Simone em relação à pergunta de algum aspecto cultural presente nas manifestações das crianças durante o faz-de-conta foi: "Quando eles brincam no 


\section{COMPREENSÃO DE PROFESSORAS ACERCA DAS BRINCADEIRAS \\ DE FAZ-DE-CONTA E DAS CULTURAS INFANTIS}

cantinho da casa, que eles brincam de mamãe e papai, ai tem bastante coisa que eles trazem de casa que eu observo bastante, eles imitam o pai e a mãe em casa”. (Simone, 13/04/2010). Neste aspecto Corsaro $(2009$, p. 32$)$ destaca que a produção da cultura não se reduz apenas a imitação, as crianças aprendem informações do mundo adulto e produz suas culturas singulares. Esse autor destaca que as crianças também compartilham atividades, valores e interesses ao interagir entre pares.

Ao trazerem para a brincadeira de faz-de-conta as ações da mãe como destacou a professora Greice, podemos considerar a representação de gênero em que as crianças se apropriam de situações que acontecem em seu grupo social, interações, espaços e relações com o outro. Para Corsaro (2009), quando a criança reproduz os elementos da cultura dela, no entanto, os aprende e os torna legítimos, levando para a brincadeira comportamentos apropriados de outros diversos espaços de interação.

A professora Fabricia respondeu de forma semelhante de que as crianças trazem elementos cultuais para o faz-de-conta: "Trazem, geralmente as meninas trazem a mamãe, a filhinha fazendo comida. Se eles vão ao parque têm a casinha, elas brincam lá e trazem os meninos como sendo filhos delas e os meninos interagem sendo pai, o irmão ou primo, é assim que eles brincam”. (Fabrícia, 20/04/2010).

Partindo dessas reflexões e conceitos atribuídos por Corsaro (2009) em relação à cultura de pares, é possível refletirmos sobre os significados que nós adultos atribuímos às crianças e às suas culturas para educação mais especificamente para as teorias Pedagógicas. Refletimos sobre como essas questões incidem em tais teorias e por consequência na prática das professoras de Educação Infantil.

As diferentes compreensões estabelecidas pelas professoras como por exemplo, na resposta da professora Fernanda voltada ao interesse da criança pelo "outro", porém, chamounos a atenção quando a professora ao perguntar às crianças o que elas queriam fazer na instituição, a resposta das crianças foi: brincar. "Eu acho que constrói, eu tenho alguns muito tímidos e isso ajuda. Têm uns que conversam muito pouco e isso ajuda muito a se interessar pelo colega, saber o nome. Porque eu vi que alguns não sabiam o nome. Se interessar pelo outro, também mostra na brincadeira que eles se interessam pelo outro. Na idade deles eu acho que o brincar é quase tudo. Quando eles vêm pra escola, tu perguntas o que eles querem fazer: é brincar. Nós como professores, educadores, temos a obrigação de orientar 


\section{COMPREENSÃO DE PROFESSORAS ACERCA DAS BRINCADEIRAS \\ DE FAZ-DE-CONTA E DAS CULTURAS INFANTIS}

essas brincadeiras, que eles aprendem brincando, porque é assim que funciona". (Fernanda, 12/05/2010).

O interesse das crianças pela brincadeira na instituição de Educação Infantil é visível pelas professoras. O que acontece geralmente são as influências e cobranças da direção, pais e outros profissionais (colegas de trabalho) de atividades dirigidas como forma de mostrar práticas pedagógicas. As crianças imaginam, criam, representam papéis, elaboram conceitos, constroem conhecimentos, reproduzem interpretativamente os adultos por meio das brincadeiras. O brincar é uma das maneiras das crianças interpretarem o mundo, assimilar objetos, se relacionar com o outro, experimentar situações e desafios, compreender a realidade e resolver situações problemas.

As crianças interpretam e reproduzem aquilo que observam. A brincadeira também transcende a realidade imediata, ou seja, há outras realidades sociais que influenciam e fazem intercâmbio com a realidade das crianças na interação com outras dimensões e/ou outras crianças com realidades diferentes da sua. No entanto, não há como mencionar o brincar sem mencionar crianças, e não há como deslocar o assunto sobre as crianças dos adultos. Desta maneira ao mencionar estes três elementos, eles nos remetem também às culturas infantis. A resposta da professora Márcia: “O brincar é tudo. É viver, é botar para fora o que eles estão sentindo, é se comunicar com a gente, botar as angústias. Não tem, não tem nada que substitua o brincar”. (Márcia, 16/04/2010)

O brincar para a professora Márcia, refere-se às expressões das crianças quando fala de sentimentos e angústias. Neste aspecto, Zanini e Leite (2008, p. 92) destacam que é "através do olhar e da escuta que o professor estará aberto a dar espaço às expressões das crianças, atuando como mediador desse processo, ampliando os fazeres, enriquecendo a expressividade e a autoria das crianças, e oferecendo-lhes liberdade para a criação". O desafio atribuído às professoras das instituições de Educação Infantil garante que a brincadeira esteja de fato presente no cotidiano e nos registros das mesmas como ponto que considera o desenvolvimento e a construção do conhecimento infantil. As atividades direcionadas parecem garantir a homogeneidade, facilitando o trabalho das professoras, porém podemos levar em conta aquilo que a criança traz do seu contexto familiar/ comunitário que podemos considerar significativo ao desenvolvimento das crianças e seus conceitos. A situação que a criança observa no universo dos adultos reproduz à sua maneira nas brincadeiras de faz-deconta. 


\section{COMPREENSÃO DE PROFESSORAS ACERCA DAS BRINCADEIRAS \\ DE FAZ-DE-CONTA E DAS CULTURAS INFANTIS}

As professoras percebem nas brincadeiras de faz-de-conta uma maneira das crianças imitarem atitudes dos adultos ou das pessoas nas quais elas interagem, no entanto, conforme Corsaro (2009), as crianças não apenas imitam os adultos, mas se apropriam criativamente das informações do mundo adulto e representam com seus pares no faz-de-conta.

Ao mencionar sobre os conhecimentos aprendidos pelas crianças, por meio do brincar, queremos destacar que as professoras podem utilizar as situações imaginárias das crianças em prol do processo de desenvolvimento das mesmas. Para a professora Kailane: "Brincar como está na nossa proposta que a gente estuda, significa extravasar. É brincando que a criança aprende. Então, o brincar é indispensável aqui na Educação Infantil. Não adianta a gente ficar com métodos escolarizantes sendo que eles têm apenas quatro, cinco, seis anos. A gente tem que primeiro pensar que tudo que a gente faz tem que ser com o lúdico com as brincadeiras, com jogos". (Kailane, 22/05/2010).

A professora relaciona o brincar com o aprender e como indispensável na Educação Infantil em que todo o trabalho é realizado com jogos e brincadeiras. A escolarização da infância priva as crianças e sua liberdade de imaginar, fantasiar, explorar o ambiente que a cerca. Para Redin (2009), o tempo da infância é ocupado por diversas atividades e exigências e cada vez mais a infância é institucionalizada e reduzida. Concordamos com o autor neste aspecto, pois é nesta perspectiva que destacamos a problemática desta pesquisa, justamente a institucionalização da infância, o "dever de aluno", cada vez mais a escolarização é antecipada por uma rigorosa rotina institucional.

As relações entre a realidade e a fantasia são variadas entre as crianças por meio do faz-de-conta, elas dão significado às coisas conforme a visão que têm da realidade que a cerca. Pelas apropriações que as crianças têm das informações do mundo real, trazem para o imaginário e reconstroem de maneira criativa tais informações. A fantasia se reporta às situações da realidade e são trazidas para o faz-de-conta, trazidas de um universo de referência - dos adultos -. Os acontecimentos reais, os objetos, as pessoas nas quais as crianças têm contato são fundamentais para a reprodução e produção das culturas infantis e servem como subsídios na construção do conhecimento e na aprendizagem das crianças pequenas.

A criança utiliza sua imaginação para transformar objetos, brinquedos ou situações em algo que tenha observado e que possa ter chamado sua atenção. Nessa perspectiva, as distribuições dos papéis que as crianças desenvolvem dentro do faz-de-conta possuem uma 


\section{COMPREENSÃO DE PROFESSORAS ACERCA DAS BRINCADEIRAS \\ DE FAZ-DE-CONTA E DAS CULTURAS INFANTIS}

característica cultural trazida do seu cotidiano. As crianças quando brincam de faz-de-conta aprendem, além de conceitos, também a se relacionar com o outro, com o meio social. Os conceitos são significativos na medida em que constroem seja com quem educa, seja entre pares. A interpretação das informações do mundo dos adultos por meio de mecanismos presentes no seu cotidiano permite às crianças partilharem conhecimentos entre si. Para Sarmento (1997), a presença do lúdico é essencial, pois a criança, diferente do adulto, leva o momento da brincadeira muito a sério. Quando as crianças brincam é aquela situação que vivencia de forma autêntica e se identifica dentro do faz-de-conta.

Assim, de acordo com esse autor, os elementos que as crianças trazem de seu cotidiano para a brincadeira de faz-de-conta são representações interpretativas que elas reproduzem na interação entre pares. "O jogo de papéis envolve mais do que a aprendizagem de conhecimentos sociais específicos; envolve também aprender a relação entre contexto e comportamento" (CORSARO, 2009, p.40). Os conhecimentos construídos pelas crianças nas brincadeiras e jogo de papéis é abrangente. As crianças além dos conhecimentos e da elaboração de conceitos também conseguem captar como se dão as relações e os comportamentos sociais.

\section{CONSIDERAÇÕES FINAIS}

A realização desta pesquisa nos possibilitou olhar para a trajetória da infância, sua construção e avanços nas pesquisas como um marco que contribui com a reflexão da prática educativa das professoras de crianças da Educação Infantil. O tema estudado e os dados indicam a compreensão das professoras em relação ao faz-de-conta e as culturas infantis e exige um exercício de reflexão intelectual que não se esgota.

As professoras da Rede Municipal de Gaspar evidenciaram pontos positivos em seus conceitos sobre o brincar de faz-de-conta das crianças e as culturas infantis, dentre eles destacamos que as professoras compreendem o faz-de-conta das crianças como sendo a principal atividade no cotidiano institucional, consideram o brincar de faz-de-conta como uma forma da criança se expressar. Consideram que por meio do brincar as crianças se soltam e expressam as suas vontades. As professoras também contemplam as brincadeiras de faz-deconta no seu planejamento. 


\section{COMPREENSÃO DE PROFESSORAS ACERCA DAS BRINCADEIRAS \\ DE FAZ-DE-CONTA E DAS CULTURAS INFANTIS}

Neste aspecto, Corsaro (2004) evidencia que "pesquisadores que estudam crianças argumentam já há muito tempo a respeito da importância de brincadeiras de dramatização de papéis para o desenvolvimento social e emocional das crianças”. Corsaro em suas pesquisas com crianças e a obtenção de dados empíricos contribui com as formas de captar elementos que caracterizam maneiras de atuar nos grupos sociais específicos, no seu caso "de crianças", seus estudos etnográficos se dão ao brincar de faz-de-conta em instituições de Educação Infantil.

As professoras percebem aspectos das culturas infantis trazidos pelas crianças de contextos não institucionais para as brincadeiras de faz-de-conta, principalmente provenientes do contexto familiar. No entanto, o faz-de-conta das crianças para as professoras é visto como imitação dos adultos, e não como reprodução interpretativa. O brincar de faz-de-conta por vezes é utilizado pelas professoras como método, recurso, estratégia ou pretexto para aprendizagem de conteúdos. Na maioria das respostas percebemos a presença de atividades direcionadas tidas como referência e primordiais no discurso sobre o planejamento das professoras. Entretanto, as professoras também evidenciaram o aspecto que trazemos na problemática desta pesquisa que é a preocupação com as crianças no futuro escolar. Nesta perspectiva de projetar a criança para o futuro é que as professoras acabam trazendo práticas escolarizantes, tornando a rotina diária das crianças em atividades direcionadas que emergem à criança ao dever de aluno, numa rigorosa rotina institucional.

Diante da relevância social do tema não foi possível esgotar todos os pontos que permeiam a brincadeira de faz-de-conta e as culturas infantis. Podemos considerar que seria um dos pontos significativos para os profissionais da área específica da Educação Infantil se as formações estiverem voltadas às especificidades da infância conforme a necessidade dos saberes dos professores. Refletir acerca de propostas que organizem os espaços, facilitem os momentos de brincadeiras de faz-de-conta das crianças, estimulem a fantasia, a imaginação e a criatividade. Conforme Tardif (2002), que o saber posiciona-se ao lado da teoria. O saber é construído paralelo à prática.

O brincar organizado é valorizado em detrimento do espontâneo como fonte de desenvolvimento e aprendizagem. As brincadeiras de faz-de-conta organizadas pelas crianças, a forma de interação com os colegas, o exercício da afetividade, da liderança são aspectos de aprender diante das relações sociais presentes nesse processo de organização das brincadeiras. 
A formação de professores pode buscar a superação da dicotomia educação/cuidado e levar em conta esses dois elementos essenciais no cotidiano da Educação Infantil pela sua especificidade. Entendemos que para responder às diversidades de situações existentes na Modernidade em instituições de Educação Infantil e também a multiplicidade de profissionais que atuam na área, que as propostas de formação sejam diferenciadas, aprofundando estudos sobre as especificidades da atuação em diferentes idades da educação de crianças de zero a cinco anos.

\section{REFERÊNCIAS}

BARDIN, Laurence. Análise de conteúdo. São Paulo. Martins Fontes. 1977.

BIKLEN, Sari; BODGAN, Robert. Investigação Qualitativa em Educação: uma introdução à teoria e aos métodos. Tradução Maria João Alavares; Sara Bahia dos Santos; Telmo Mourinho Baptista. Portugal: Porto, 1994. (Coleção Ciências da Educação).

CERISARA, Ana Beatriz. Rousseau: a educação na infância, São Paulo: Scipione, 2002.

COLLING; Graciele de Souza. ITEN, Ana Paula de Oliveira. A dimensão sociocultural presente na brincadeira de faz-de-conta de crianças de 4 anos.Blumenau, TCC- FURB. 2008.

COHN, Clarice. Antropologia da criança. Rio de Janeiro: J. Zahar, 2005.

CORSARO, William. A. A reprodução interpretativa no brincar ao "faz-de-conta" das crianças. Revista Educação, sociedade \& culturas. Página 113-133. Porto, 2002.

CORSARO, William. Ação coletiva e agência nas culturas de pares de crianças. Tradução Manuela Ferreira. São Paulo. Ática, 2004.

CRUZ, Silvia Helena Vieira. A formação inicial e continuada e a profissionalidade específica dos docentes que atuam na educação infantil. DALBEN, Ângela. DINIZ, Júlio. LEAL, Leiva. SANTOS, Lucíola. (org. da coleção). Coleção Didática e Prática de Ensino. 
ENDIPE, 2010. Convergências e Tensões no Campo da Formação e do Trabalho docente: Políticas e práticas educacionais.

GANDIN, Danilo. Planejamento como prática educativa. $11^{\circ}$ edição, São Paulo. Loyola, 2000 .

GASPAR. Proposta Pedagógica da Rede Municipal de Educação Infantil. Secretaria da Educação, Gaspar SC. 2004.

PIMENTA, Selma Garrido. Saberes pedagógicos e atividade docente. (organização). 2 ed. São Paulo, 2000.

PINTO, Manuel. MANUEL, Jacinto sarmento. As crianças, contextos e identidades. Universidade do Minho, Centro de Estudos da Criança. 1997.

QUIVY, Raymond e CAMPENHOUDT, Luc. Manual de investigação em ciências sociais. Lisboa: Gradiva. V.- 1993.

REDIN, Marita Martins. Crianças e suas culturas singulares. São Paulo, Cortez, 2009.

ROCHA, Eloisa A C. A Pesquisa em Educação Infantil no Brasil: Trajetória recente e perspectiva de consolidação de uma Pedagogia da Educação Infantil. Florianópolis: UFSC - Centro de Ciências da Educação. Teses (doutorado) - Núcleo de publicações, 1999.

SARMENTO, Manuel Jacinto. As Culturas da Infância nas Encruzilhadas da Segunda Modernidade. Universidade do Minho/ ASA. Portugal, p. 9-35. 2004.

TARDIF, Maurice. Saberes docentes e formação profissional. Petrópolis, RJ: Vozes, 2002.

VYGOTSKY, L.S. Formação social da mente. Martins Fontes, 1989.

ZANINI, Juliana Quint dos Santos. LEITE, Rachel Winz. Sobre afetividade e construção de vínculos na educação infantil. OSTETTO, Luciana Esmeralda (orgs). Educação Infantil, saberes e fazeres da formação de professores. Campinas, São Paulo, Papirus, 2008. 
